\title{
The Concept of the Ergonomic Spectrum
}

\author{
Yozo Yamada ${ }^{1}$, Efi Yuliati Yovi ${ }^{2}$, Dianne Staal Wästerlund ${ }^{3}$, John J. Garland ${ }^{4}$, Janusz M. Sowa ${ }^{5}$ \\ ${ }^{1}$ Graduate School of Bio-Agricultural Sciences, Nagoya University, Nagoya, Japan \\ ${ }^{2}$ Faculty of Forestry, Bogor Agricultural University, Bogor, Indonesia \\ ${ }^{3}$ Department of Forest Resource Management, Swedish University of Agricultural Sciences, Umeå, Sweden \\ ${ }^{4}$ Garland \& Associates, Waldport, USA \\ ${ }^{5}$ Department of Forest and Wood Utilization, University of Agriculture in Krakow, Krakow, Poland \\ Email: yozo@agr.nagoya-u.ac.jp
}

Received November $14^{\text {th }}$, 2012; revised December $17^{\text {th }}$, 2012; accepted December $27^{\text {th }}$, 2012

\begin{abstract}
Forestry conditions differ among regions and nations. Moreover, labor costs, forestry mechanization, and environmental impacts are also different. These factors directly or indirectly influence the ergonomic state of nations. The ergonomic state of a nation can be described in terms of ergonomic factors such as labor productivity, work accidents, physiological burden, and stress. Labor productivity and work accidents can be defined as income or condition factors, and physiological burden and stress as outcome or result factors. Thus, the value of outcome factors must be examined in relationship to income factors. On the ergonomic spectrum, each factor can be conceived as a continuum from a negative to a positive ergonomic status. All factors can be set in a line, and the present state of each nation is indicated by a profile formed by the assembled factors. The locations of nations along the two-dimensional coordinates of the world standard can be realized by an ergonomic spectrum. Moreover, future directions for improvement can be obtained by reference to the three-dimensional coordinates, which include the axis of time.
\end{abstract}

Keywords: Ergonomic Spectrum; Economic Situation; Forestry Condition; Working Condition; Work Accident

\section{Introduction}

Globally, forest engineering has been shifting from manual to mechanized work. Consequently, ergonomic issues have changed from physical or physiological burdens of forestry workers to psycho-physiological stressors of machine operators. However, many developing countries continue to rely on manual work for most of their forestry operations. Manual work is a classic ergonomic issue, and it remains significant in developing countries. Moreover, some countries, such as Japan, are located midway between manual and mechanized forestry. Forestry mechanization has spread in Japan except in the area of felling operations due to the steep and complicated terrain. This situation cannot be improved unless an innovative technique is developed to overcome the adverse natural conditions.

Manual felling operations with a chainsaw have been recognized globally as one of the most dangerous jobs in forestry, and many studies have been conducted from a safety perspective. For example, Hammond studied critical safety behaviors of differently skilled workers using a helmet camera in the USA (Hammond et al., 2011). Bentley noted the potential for injury among inexperienced fellers in New Zealand and claimed that felling safety is dependent upon an appropriate assessment of hazards and good judgment with respect to decisions regarding felling (Bentley et al., 2005). Felling operations in Japan have been the most dangerous forestry work during this half century (Oka et al., 2011), and many severe accidents have occurred during manual felling operations in Sweden among private forest owners (Lindroos \& Burstrom, 2010).

Wearing protective devices to reduce work accidents during manual felling operations is one of the most effective direct safety countermeasures. Kashima claimed that wearing protec- tive trousers while operating a chainsaw results in a $60 \%$ decreases in lower body injuries (Kashima \& Uemura, 2008). However, many of the protective devices have been developed in cool and dry climate countries and are not suitable for use in tropical or wet temperate regions. Workers in those regions hate to wear protective devices, even helmets and gloves, because they are uncomfortable. Wästerlund researched heat stress in forestry and argued for a standard research method to determine protective clothing comfort (Wästerlund, 1998). Holland evaluated the ventilation capacity of various helmets for forest harvesting (Holland et al., 2002).

Ergonomic issues vary in every nation, as each has different forestry conditions. Although Feyer compared fatal occupational injuries among US, Australian, and New Zealand workers (Feyer et al., 2001), very few cooperative studies have involved multiple nations. Thus, it is difficult to describe the present ergonomic state of each nation using a simple world standard.

This report offers the ergonomic spectrum as a new idea to objectively identify current forestry ergonomic conditions in each nation and to identify the actual and more preferred future direction to improve each nation's ergonomic conditions. At first, we introduce the concept of ergonomic spectrum, and then explain how to select indices for using the ergonomic spectrum, and finally show two experimental examples.

\section{Concept of Ergonomic Spectrum}

Everyone wants to eliminate forestry accidents. If this occurs thorough forestry mechanization, forestry work accidents will decrease dramatically, including in felling operations. Unfortunately, it is quite difficult to realize this scenario because of the 
forestry conditions in each nation. Work accidents are influenced significantly by forestry conditions, which are influenced by national and regional indigenous characteristics such as geography, topography, climate, vegetation, population, wood demand, wood trade, and economic and social conditions. Moreover, labor costs, forestry mechanization, labor productivity, and environmental impacts also differ among nations. Thus, working conditions directly or indirectly influence the ergonomic state of each nation.

The ergonomic state of a nation can be estimated through ergonomic factors such as work accidents, physiological burden, and stress. These factors indicate the current ergonomic situation based on forestry activities in each nation, and improvement in these factors would result in safer conditions, lighter work and stress loads, and more comfortable working conditions. If forestry and working conditions are defined as income or conditions, then ergonomic factors can be defined as outcome or results. The value of outcome factors must be examined relation to the income factors.

However, it is unrealistic to comparatively evaluate factors that differ in substances, units, and scales. Thus, the spectrum concept is used to allow a clear comparison among different ergonomic situations in the world.

With respect to a spectrum, the emotional spectrum and the recreational opportunity spectrum are well known to include some vectors. The emotional spectrum (ES) can evaluate an emotional state of human from the electroencephalogram, and is composed of four element emotion vectors; anger, sadness, joy, and relaxation. The recreation opportunity spectrum (ROS) is an applied example. The ROS is a combination of physical, biological, social, and managerial conditions that give recreational value to a place (Clark \& Stankey, 1979).

The basic concept of the ergonomic spectrum is similar to that of the ES and the ROS. Whereas the ROS separates nations into seven classes from the least to the most remote (British Columbia Resources Inventory Committee, 1998), the ergonomic spectrum is more complicated and not as easily divided into patterns.

As shown in Figure 1, each factor is represented along a continuum from a negative to a positive ergonomic state, with a negative state shown in orange, and a positive one in green. All factors are set in a line, and the present state of each nation is indicated by a cross-section of the assembled factors. It appears like a spectrum; thus, it is easy to recognize where a nation is located compared to the world standard using the two-dimensional coordinates. Moreover, the directions needed for improvement can be shown in a three-dimensional coordinates that include the axis of time.

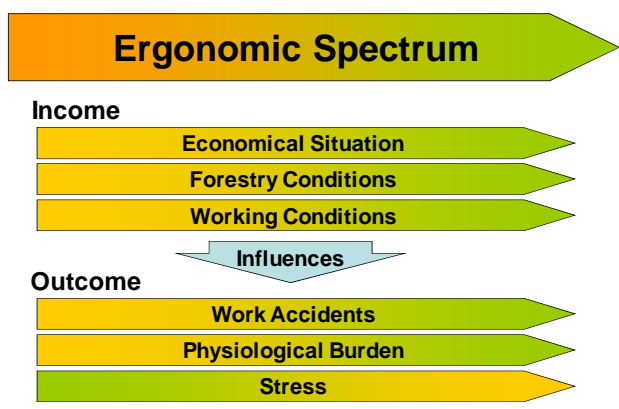

Figure 1.

Concept of the ergonomic spectrum.

\section{Selection of Ergonomic Spectrum Indices}

Indices for the ergonomic spectrum were defined as the economic situation, forestry conditions, working conditions, and work accidents. The first three factors are income factors, and the last is an outcome factor. Physiological burden and stress could not be included because these types of data are difficult to gather from official reports. Although researchers sometimes report these data, the studies are often case studies and usually do not represent average burdens of all workers in a country. Furthermore, other factors are applicable to the ergonomic spectrum, but data on these could not be obtained for every country; thus, they were eliminated from this study.

\section{Economical Situation}

National economic and social situations have great impact on forestry as an industry. The economic situation of a nation can be described by many factors such as nominal or real gross domestic product (GDP), nominal or real gross domestic index, the domestic population, consumer price index, and Engel's coefficient. In this study, the nominal GDP per person, as an index of the national economic situation, and Engel's Coefficient, as an index of rich and poor, were selected for use in the ergonomic spectrum.

\section{Forestry Conditions}

Forestry conditions are characterized by climate zone, average slope gradient, forest coverage rate, artificial forest rate, planted species, wood demand, wood self-support ratio, forest road density, and forestry mechanization rate. Data on some of these factors are difficult to obtain because no description is available in official reports. In this study, the forest coverage rate, as an index of potential wood resources, and the self-support ratio of timber, as an index of logging activities, were selected.

\section{Working Conditions}

Working conditions can have a crucial impact on work accidents, physiological burden, stress, and decision making during forestry work. Working conditions include wage, number of forestry workers, the age index, management area, and labor productivity. In this study, the average wage, average management area, and average productivity were selected as representtative factors. The average management area per person was calculated by dividing the forest area by the number of forestry workers. Although the actual number of workers cannot be compared against figures for other countries, management area can be estimated by the number of workers. The average productivity per year per person, which is calculated by dividing felling volume by the number of forestry workers, also indicates the degree of mechanization.

\section{Work Accidents}

Work accidents are external factors or objective variables explained by the economic situation, forestry circumstances, and working conditions. In this study, the work accident rate and the fatal accident rate were selected as factors. These are expressed as the rate of workers injured or killed per 1 million felled trees. An effort must be made to decrease these objective factors through every possible means. Unfortunately, Indonesia 
has not surveyed the number of workers injured and killed in their forestry operations.

\section{Experimental Examples}

Data of nine factors for the ergonomic spectrum were obtained from official reports from five countries, Sweden, USA, Poland, Indonesia, and Japan, to compare the ergonomic situations among them. Moreover, data were gathered at five different times in Japan, namely 1970, 1980, 1990, 2000, and 2010, to observe changes in the ergonomic situation.

\section{Comparison of Ergonomic Spectra among the Five Nations}

Figure 2 shows a comparison of the ergonomic situations among the five countries. The right-hand side of the graph is the desirable situation. Sweden's profile shows values mostly well to the right side, with little variation, whereas values for the other countries range from values toward the left-hand side to values approaching the right-hand side. The five countries show quite different profiles. The USA maintains a positive status in terms of economic situation, number of work accidents, and management area but earns low or moderate scores for forest coverage rate, the self-support ratio, wages, and productivity. Poland maintains low or medium status for the economic situation, forestry conditions, and working conditions but scores high for work accidents. Indonesia maintains low scores for their economic situation and working conditions but gets the highest marks for self-support ratio. Japan fluctuates wildly among factors. Japan gets high marks for nominal GDP, forest coverage rate, and wages. However, the high wages are due to appreciation of the yen against the US dollar. In contrast, Japan gets low scores for the self-support ratio, management area, and productivity, which are significant problems in the Japanese forestry industry. Moreover, the work and fatal accident rates are worse than those in the other countries.

The forest coverage rate is fixed in each country, and the nominal GDP and Engel's coefficient cannot be improved by the forestry sector. The self-support ratio and wage could be changed if forestry realizes a revitalization. Management area and productivity can be improved by multi-functional mechanization, but it is not easy to promote multi-functional machines in Japan and Indonesia. Without high mechanization, the accident rates can be reduced only by wearing protective de-

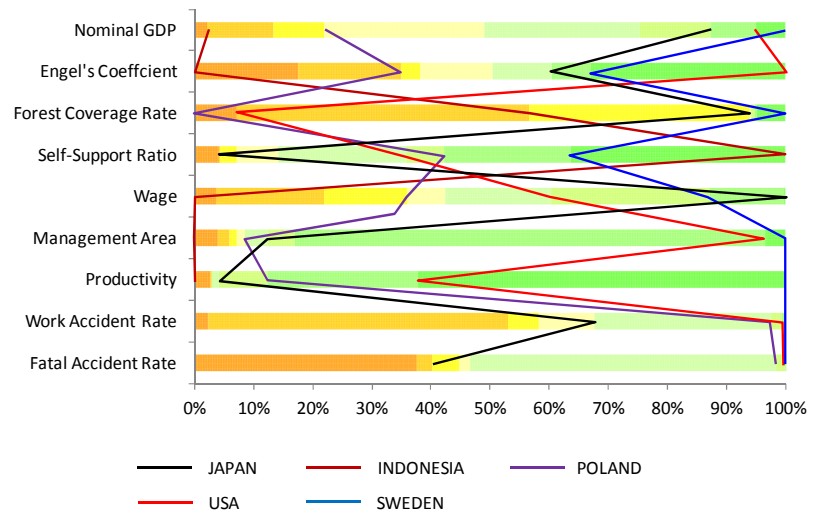

Figure 2.

Comparison of the ergonomic spectra among the five nations. vices and safety training for forestry workers.

\section{Changes in the Japanese Ergonomic Spectrum}

Figure 3 shows the changes in the Japanese ergonomic spectrum over four decades. In 1970, values for all factors except forest coverage rate were low. In 1980, nominal GDP, Engel's coefficient, and wage increased gradually. Notably, the fatal accident rate decreased largely, but the work accident rate was the worst. In 1990, the former three factors continued to increase gradually, and the work accident rate improved dramatically. Since 2000, the former three factors have continued to increase, and the work accident rate has improved slightly. The fatal accident rate has not changed since 1980 .

Although wages increased dramatically due to the high yen, the actual wage was not so high and has actually decreased since 2000. The nominal GDP and Engel's coefficient have increased steadily, and productivity and management area have increased slightly. Improving those factors in Japan will not occur smoothly because of the difficulties of multi-functional mechanization.

The work accident rate improved largely from 1980 to 1990. However, improvement has slowed in the past two decades. Moreover, the fatal accident rate has become slightly worse since 2000. Manual felling remains common in Japanese forestry. The reduction in work injuries and fatal accidents is the most significant and urgent issue. In the future, Japan should struggle to improve work conditions, fatal accident rates, productivity, and the self-support ratio.

\section{Conclusion}

We can appreciate the ergonomic situation of Japan in relation the world using the ergonomic spectrum. Moreover, we can identify the direction for improvement in our forestry ergonomic situation based on the changes in the ergonomic situation through the past several decades. In other words, we can understand easily where we are now and which directions we should improve.

However, the following problems must be solved for the ergonomic spectrum to become a useful tool. The first problem is factor selection. Which factors should we choose for the ergonomic spectrum? We must discuss whether the factors are sufficient to show the actual ergonomic situation. Moreover, we must examine whether a factor can be corrected even if it is

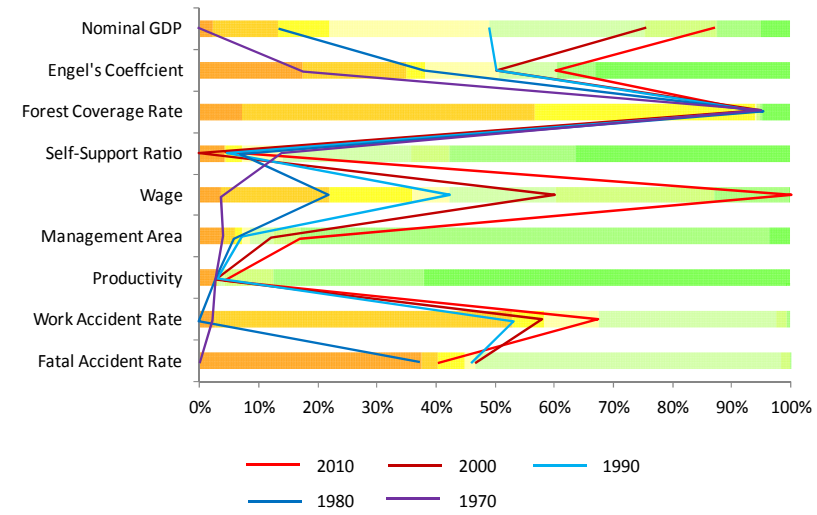

Figure 3.

Changes in the Japanese ergonomic spectrum. 


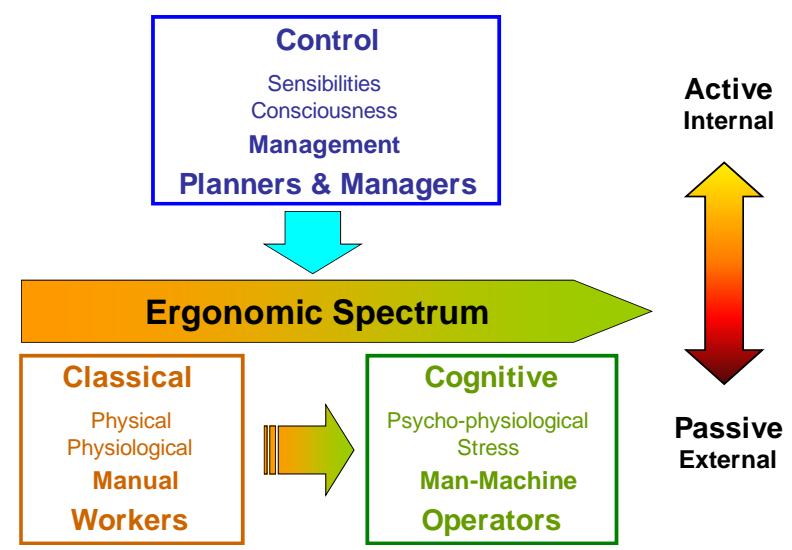

Figure 4.

Ergonomic strategy based on the ergonomic spectrum.

significant. Some countries may not have official reports or technical studies on some factors such as work accidents, physiological burden, and stress. Although it is sometimes suitable for some factors to be described qualitatively, whether those qualitative factors should become part of the ergonomic spectrum must be considered.

The second problem is differences among operations. Felling is the most dangerous manual operation, as it requires the use of a chainsaw. In Japan, delimbing and bucking operations have become safer due to more widespread use of processors. We can select suitable operations according to what we want to know. In this study, all forestry operations and all data were considered.

The third problem is classification of the ergonomic spectrum. In this study, the five countries displayed characteristically different spectra. However, it was not clarified whether those spectra represented each situation. Thus, more data must be collected from more countries if we are to describe more groups using the spectrum.

The fourth problem is the need to consider which elements of the ergonomic spectrum should be targeted for improvement. It may be true that the ultimate goal is the same throughout the world. Surely, no one wants accidents in the work place. However, in each nation, some factors can be improved and others are indigenous to the country and cannot be improved. For example, Japan cannot reach the same ergonomic situation as Sweden because its climate and terrain are different. Thus, we must find another goal that is suitable and can be accomplished. The direction of improvement is different for different countries. Studying changes in the ergonomic situation will help to identify appropriate directions for change.

The ergonomic spectrum is intended mainly for forestry workers and operators to improve their working conditions. Although improvements are traditionally basic and essential issues in ergonomics, they cannot be accomplished without the help of management, local officials, owners, planners, supervisors, and leaders. In this sense, improvements can be defined as external and passive from the point of view of workers and operators.

We must think of extending future ergonomics to forest management control spheres (Figure 4). Control ergonomics, which is based on the ergonomic spectrum, aims to enhance the sensibilities and consciousness of management and fosters internal change in each manager in working not only with staff but also with workers and operators. It is also concerned with classical ergonomics and cognitive ergonomics and considers management philosophy, design, decision making, social responsibility, evaluation, improvement, and education and training for workers and operators. In this sense, control ergonomics can be defined as active ergonomics.

\section{REFERENCES}

Bentley, T. A., Parker, R. J., \& Ashby, L. (2005). Understanding felling safety in the New Zealand forest industry. Applied Ergonomics, 36, 165-175. doi:10.1016/j.apergo.2004.10.009

British Columbia Resources Inventory Committee (1998). Recreation opportunity spectrum inventory: Procedures and standard manual Ver.3.0. Resources Inventory Committee, 39.

Clark, R. N., \& Stankey, G. H. (1974). The recreation opportunity spectrum: A framework for planning, management, and research. USDA Forest Service Research Paper PNW-98.

Feyer, A. M., Willamson, A. M., Stout, N., Driscoll, T., Usher, H., \& Langley, J. D. (2001). Comparison of work related fatal injuries in the United States, Australia, and New Zealand: Method and overall findings. Injury Prevention, 7, 22-28. doi:10.1136/ip.7.1.22

Hammond, T. R., Rischitelli, G., \& Wimer, J. A. (2011). Defining critical safety behaviors in a point-of-view video observation study of tree fallers at work. International Journal of Occupational and Environmental Health, 17, 301-306. doi:10.1179/107735211799041823

Holland, E. J., Laing, R. M., Lemmon, T. L., \& Niven, B. E. (2002). Helmet design to facilitate thermoneutrality during forest harvesting. Ergonomics, 45, 699-716. doi:10.1080/00140130210159959

Kashima, J., \& Uemura, T. (2012). Report on injured parts by saw-chain in chain-saw operations and protective effect of protective clothes. Journal of the Ceramic Society of Japan, 22, 275-278.

Lindroos, O., \& Burstrom, L. (2010). Accident rates and types among self-employed private forest owners. Accident Analysis \& Prevention, 42, 1729-1735. doi:10.1016/j.aap.2010.04.013

Musha, T., Terasaki, Y., Haque, H. A., \& Ivanitsky, G. A. (1997). Feature extaction from EEGs associated with emotions. Artificial Life and Robotics, 1, 15-19. doi:10.1007/BF02471106

Oka, M., Nakazawa, M., Sasaki, T., Yoshida, C., Uemura, T., Kashima, J., \& Kato, T. (2011). Studies on the forestry death disaster of introduction of high performance forestry machines in 10th year. Journal of the Ceramic Society of Japan, 26, 27-34.

Wästerlund, D. S. (1998) A review of heat stress research with application to forestry. Applied Ergonomics, 29, 179-183. doi:10.1016/S0003-6870(97)00063-X 